\title{
Neosartorya fischeri (Wehmer) Malloch \& Cain
}

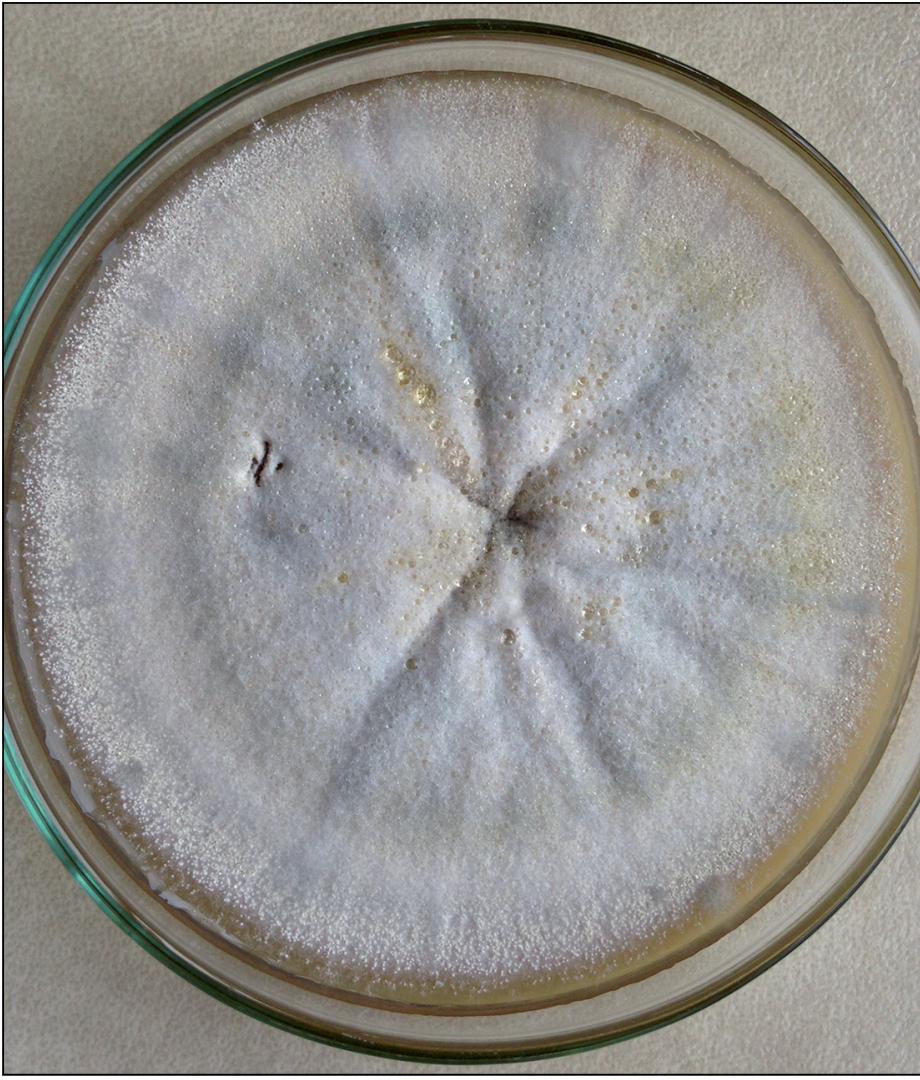

Figura 1. Colonia de rápido crecimiento a los 10 días en CYA25, obtenida de cultivar la expectoración inducida de una paciente con aspergilosis broncopulmonar alérgica.

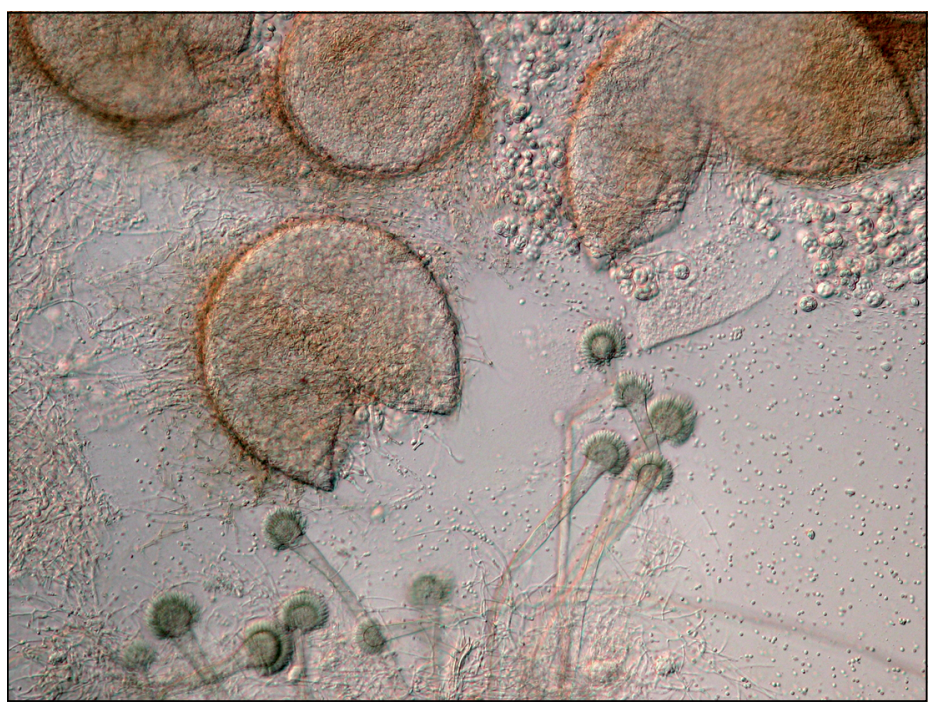

Figura 3. Cleistotecios, ascos con ascosporas y estado anamorfo en un campo. Visión microscópica. 40X.

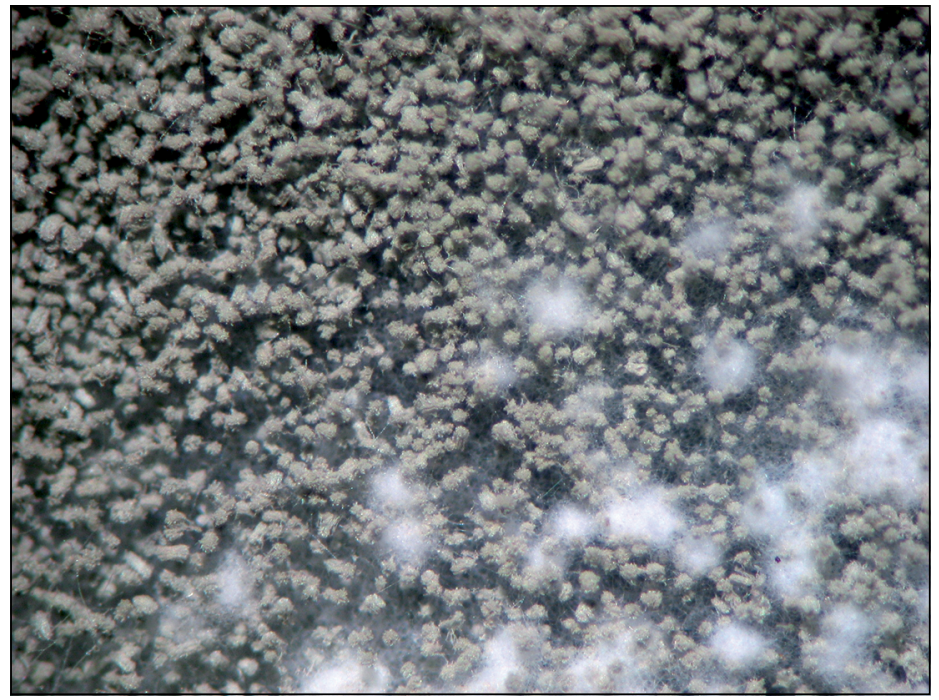

Figura 2. Múltiples cleistotecios recubiertos por hifas blanquecinas entre el estado anamorfo (A. fisherianus).Visión con lupa estereoscópica. 40X.

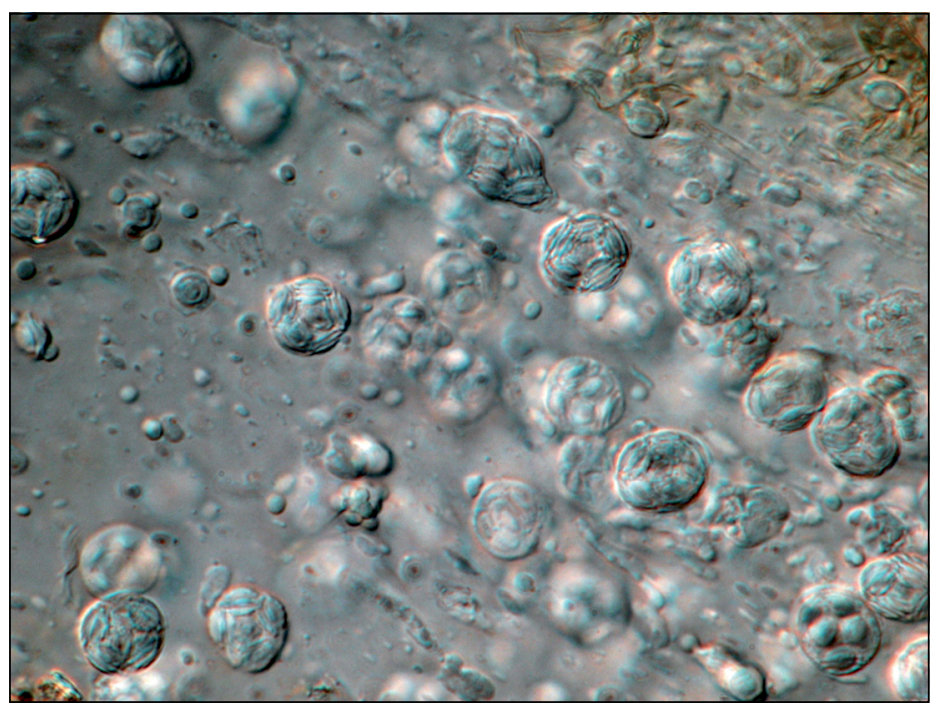

Figura 4. Ascos con ascosporas hialinas lenticulares con bordes sobresalientes. Visión microscópica. 100X. 


\section{Neosartorya fischeri (Wehmer) Malloch \& Cain}

Las especies de Aspergillus Link y sus estados sexuales (Eurotium, Emericella y Neosartorya) se consideran entre los organismos de más amplia distribución en la naturaleza, capaces de colonizar una gran variedad de substratos en los diferentes nichos ecológicos y climas. Frecuentemente, son contaminantes de distintos tipos de alimentos, granos, suelos, bosques subtropicales y ambientes internos, entre otros.

Esta especie fue descrita por primera vez en 1907 por Wehmer como A. fischeri y reclasificado en 1972 por Malloch \& Cain como N. fischeri, con su anamorfo en A. fischerianus descrito por Samson \& W. Gams en 1985.

Aunque $N$. fischeri pertenece a la misma sección (Fumigati) que hongos como A. fumigatus, A. turcosus o A. lentulus, rara vez se reportan infecciones en humanos. Estas incluyen casos de infección diseminada en paciente inmunocomprometido, endocarditis relacionada a cirugía pediátrica de tetralogía de Fallot, micosis pulmonar en paciente con mieloma, queratitis micótica y espondilodiscitis. También se han descrito como patógenas oportunistas otras especies relacionadas, como N. hiratsukae, N. pseudofischeri, N. udagawae, N. laciniosa.

Características macroscópicas: Colonias que crecen rápidamente (más de $40 \mathrm{~mm}$ en agar CYA25 a los siete días de cultivo), blanquecinas con tonos gris-azul, reverso blanquecino a rosado. Abundante presencia de cleistotecios hialinos o de color crema que se pueden observar con lupa estereoscópica o a simple vista (Figura 1 y 2 ).

Características microscópicas: Anamorfo semejante a A. fumigatus, con cabezas columnares, vesículas piriformes, monoseriadas; conidios esféricos a elipsoidales, lisos a finamente rugosos, 2,5-3,5 x 2-3 $\mu$ m. Cleistotecios presentes, tomentosos, hialinos a crema, hasta 400 micras de diámetro (Figura 3); peridio pseudoparenquimatoso, delgado, ascos esféricos a subesférica con ocho ascosporas de 10-12 × 10,8 micras. Ascosporas hialinas, lenticulares a esféricas con borde sobresaliente 5-8 x 4-5 $\mu \mathrm{m}$, con ascosporas (Figura 4).

Fisiologia: Presenta buen crecimiento a $37^{\circ} \mathrm{C}$.

Identificación molecular: La secuenciación de los genes de $\beta$-tubulina, calmodulina y actina son importantes en la diferenciación de otras especies cercanas filogenéticamente.

Tratamiento: Puede utilizarse voriconazol, itraconazol o dosis elevadas de anfotericina en formulación lipídica; sin embargo, se recomienda determinación de CIM según recomendación de CLSI.

\section{Referencias bibliográficas}

1.- Piontelli E. Aportes morfotaxonómicos en el género Aspergillus Link: claves para las especies ambientales y clínicas más comunes. Bol Micol 2008; 23: 49-66.

2.- Lonial S, Williams L, Carrum G, Ostrowski M, McCarthy P. Neosartorya fischeri: an invasive fungal pathogen in an allogeneic bone marrow transplant patient. Bone Marrow Transplant 1997; 19: 753-5.

3.- Summerbell R C, de Repentigny L, Chartrand C, St. Germain G. Graft-related endocarditis caused by Neosartorya fischeri var. spinosa. J Clin Microbiol 1992: 1580-2.

4.- Samson R A, Hong S, Peterson S W, Frisvad J C, Varga J. Polyphasic taxonomy of Aspergillus section Fumigati and its teleomorph Neosartorya. Stud Mycol 2007; 59: 147-203.

Rodrigo Cruz y Eduardo Piontelli Laboratorio de Micología Universidad de Valparaíso. 